\title{
Peptide-Directed Microstructure Formation of Polymers in Organic Media
}

Corresponding author: Hans G. Börner

Other authors: Jens Hentschel

Max Planck Institute of Colloids and Interfaces, Research Campus Golm, D-14424, Potsdam, Germany. Email: hans.boerner@mpikg.mpg.de 


\section{Experimental details}

Materials: Diisopropylethylamine (DIPEA; Acros, peptide grade), piperidine (Acros, peptide grade), trifluoracetic acid (TFA; Acros, peptide grade), N,N-diisopropylcarbodiimide (DIC; Fluka, 99\%) and 1-methyl-imidazole (NMI; Fluka, 99+\%) have been applied as received. Copper(I) bromide $(\mathrm{CuBr}$; Aldrich, 98\%) was purified according to standard procedure. $^{1}$ N,N,N',N',N',-pentamethyldiethylenetriamine (PMDETA; Aldrich, 99\%), 2bromopropionic acid (Aldrich, 99+\%), n-butyl acrylate (nBA, Aldrich, 99\%), dichloromethane (DCM; IRIS Biotech GmbH, peptide grade) and N,N-dimethylformamide (DMF; Aldrich, 99+\%) were distilled prior to use. All other reagents were used as received from Aldrich without further purification.

Fmoc-amino acid derivatives (Fmoc- $\operatorname{Thr}(t \mathrm{Bu}) \mathrm{OH}, t \mathrm{Boc}-\mathrm{Thr} \mathrm{OH}$, Fmoc-Val OH, FmocGly $\mathrm{OH}, \quad$ 2-(1H-benzotriazole-1-yl)-1,1,3,3-tetramethyluronium hexafluorophosphate (HBTU), N-methyl-2-pyrrolidone (NMP, 99.9+\%, peptide synthesis grade) were used as received from IRIS Biotech GmbH, Germany. Benzotriazole-1-yl-oxy-tris-pyrrolidinophosphonium hexafluorophosphate (PyBOP) and Fmoc-(4-nitro)Phe OH (Fmoc-nPhe OH) were used as received from Applied Biosystems, Germany. TentaGel ${ }^{\circledR}$ polystyrene-(2chlorotrityl chloride) resin (pS-PEO-(2-Cl-trt)Cl); loading: $0.3 \mathrm{mmol} / \mathrm{g}$ ) was received from Rapp, Polymere GmbH, Tuebingen, Germany and loaded with Fmoc-Gly OH by following standard procedures to yield pS-PEO-(2-Cl-trt)-Gly-NHFmoc (I) with a loading of 0.25 $\mathrm{mmol} / \mathrm{g})^{2}$ 
Instrumentation: The semi-automated synthesis of the conjugate was performed on an ABI 433a peptide synthesizer (Applied Biosystems, Germany) for the automated reaction steps.

Mass spectrometry was performed on a Shimadzu QP8000 electrospray-MS (ESI-MS) (Shimadzu, Germany) with $\mathrm{N}_{2}$ as carrier gas $\left(4.5 \mathrm{~L} / \mathrm{min}\right.$ ), an injector temperature of $150{ }^{\circ} \mathrm{C}$ and an acceleration voltage of $4.5 \mathrm{kV}$. The $0.1 \mathrm{mg} / \mathrm{mL}$ samples in methanol with $0.1 \%$ formic acid were injected and the detection proceeded in the positive modus with a detector voltage of $1.6 \mathrm{kV}$. Nuclear magnetic resonance spectra (NMR) were recorded on a Bruker DPX-400 Spectrometer at $400.1 \mathrm{MHz}$ in $\mathrm{CDCl}_{3}, \mathrm{MeOH}-\mathrm{d}_{4}$ or DMSO- $\mathrm{d}_{6}$. GPC measurements were carried out in THF (flow rate $1 \mathrm{~mL} / \mathrm{min}$ ) using three $5 \mu$-MZ-SDV columns $\left(10^{3}, 10^{5}\right.$ and $10^{6}$ A). The detection was performed with a RI- (Shodex RI-71) and a UV-Detector (TSP UV 1000; 260 nm). For calibration linear pS-standards (PSS, Germany) were used.

Circular dichroism UV spectra (CD) were recorded on a Jasco 715 CD spectrometer in methanol solution $(0.5 \mathrm{mg} / \mathrm{mL}$ sample concentration $)$. Fourier transformation infrared spectroscopy (FT-IR) was performed on a BioRad FTS6000 spectrometer using a Golden Gate arrangement (Single Reflection Diamond ATR). The IV was measured as a solid directly after freeze drying, while a solution of $\mathrm{V}$ was dried as thin film directly on the ATR crystal prior to the measurements.

Transmission electron microscopy (TEM) was performed on a Zeiss EM $912 \Omega$ instrument at an acceleration voltage of $120 \mathrm{kV}$. The samples were air-dried on carbon-coated copper grids (solution $0.2 \mathrm{mg} / \mathrm{mL}$ ). Atomic force microscopy (AFM) was performed on a NanoScope IIIa device (Veeco Instruments, Santa Barbara, CA) in tapping mode. Commercial silicon tips (Type NCR-W) were used with a tip radius $<10 \mathrm{~nm}$, employing a constant force of $42 \mathrm{~N} \mathrm{~m}^{-1}$ at a resonance frequency of $285 \mathrm{kHz}$. The image was recorded on a $10 \times 10 \mu \mathrm{m}$ e-scanner. The samples were either spin-coated $(3000 \mathrm{rpm})$ from solution $(0.05-0.5 \mathrm{mg} / \mathrm{mL})$ or air-dried on freshly cleaved Mica substrates. Analyses of the aggregate dimension were carried out on a sample exhibiting separated structures by averaging over at least 30 values. 


\section{Synthesis of the carboxyl end-functionalized poly(n-butylacrylate), III by ATRP}

The benzyl 2-bromopropanoate, exhibiting a benzyl ester protected carboxyl functionality was synthesized according to De-Cheng et al. ${ }^{3}$ and used as a functional initiator for the ATRP of $n$ BA. The polymerization was performed by adding $\mathrm{CuBr}(718 \mathrm{mg}, 5 \mathrm{mmol})$ and $\mathrm{CuBr}_{2}(45 \mathrm{mg}, 0.2 \mathrm{mmol})$ to a Schlenk flask, which was purged three times with argon. To this, a degassed mixture of $11 \mathrm{~mL}$ acetonitrile, $28.7 \mathrm{~mL}$ of $n \mathrm{BA}(200 \mathrm{mmol})$ and $1.1 \mathrm{~mL}$ of PMDETA (5.2 mmol) was added via syringe transfer under inert gas atmosphere. The reaction mixture was stirred for $1 \mathrm{~h}$ to allow copper complex formation, preheated to $60{ }^{\circ} \mathrm{C}$ and subsequently the polymerization was initiated by the addition of a degassed solution of benzyl 2-bromopropanoate $(1.75 \mathrm{ml}, 10 \mathrm{mmol})$ in acetonitrile $(2 \mathrm{~mL})$. After $2 \mathrm{~h}$ the polymerization was stopped by cooling the mixture to room temperature and exposing it to air. After evaporating the solvent and the residual monomer under vacuum, the mixture was diluted with acetone, filtered through a alumina column to remove the catalyst and the polymer was precipitated in aqueous methanol (20vol.\% water) to yield the precursor polymer $(17.2 \mathrm{~g}, 82 \%)$. From this the benzyl ester protecting group of the $\alpha$-carboxylate functionality could be selectively removed under reductive conditions (ammonium formate, $\mathrm{Pd} / \mathrm{C}$ (10wt.\%); absolute ethanol) giving III (yield 75\%) by following a procedure that was described previously. ${ }^{4}$

Analysis of III: ${ }^{1} \mathrm{H}-\mathrm{NMR}\left(\mathrm{CDCl}_{3}\right): \delta=0.91-0.95$ (t, $\left.46 \mathrm{H}, \mathrm{CH}_{2}-\mathrm{CH}_{3}\right), 1.18-1.19$ (d, $\left.3 \mathrm{H}, \mathrm{CH}-\mathrm{C}_{3}\right), 1.36-1.38$ (b, $\left.32 \mathrm{H}, \mathrm{C}_{2}-\mathrm{CH}_{3}\right), 1.59-1.91$ (b, $64 \mathrm{H}, \mathrm{CH}_{2}-\underline{\mathrm{C}}_{2}-\mathrm{CH}_{2}+\mathrm{CH}-$ $\left.\mathrm{C}_{2}\right), 2.28$ (b, $\left.16 \mathrm{H}, \mathrm{C} \underline{H}-\mathrm{CH}_{2}\right) 4.05$ (b, $\left.32 \mathrm{H}, \mathrm{O}-\mathrm{C}_{2}\right)$ ppm; no resonances detectable characteristic for the benzyl ester group at 5.13 and 7.33 ppm. FT-IR: $v\left(\mathrm{~cm}^{-1}\right): 2960-2874$ (s, C-H), 1734 (s, C=O), 1166 (w, O-H); MALDI-TOF-MS: 2 homologous series with $128 \mathrm{Da}$ mass of the repeat units, each $\left(\mathrm{m} / \mathrm{z}_{\text {(max intensity) }} 2035.8\right.$ and 2019.8 , which can be assigned to [M $+\mathrm{K}]^{+}$and $[\mathrm{M}+\mathrm{Na}]^{+}$, respectively with $15 n \mathrm{BA}$ repeat units and an end group mass of 74.1 Da (propionic acid)); GPC: (THF, pS-standards) $M_{n}=2300 \mathrm{~g} / \mathrm{mol}, \mathrm{DP}_{\mathrm{n}}=18, \mathrm{M}_{\mathrm{w}} / \mathrm{M}_{\mathrm{n}}=1.13$. 


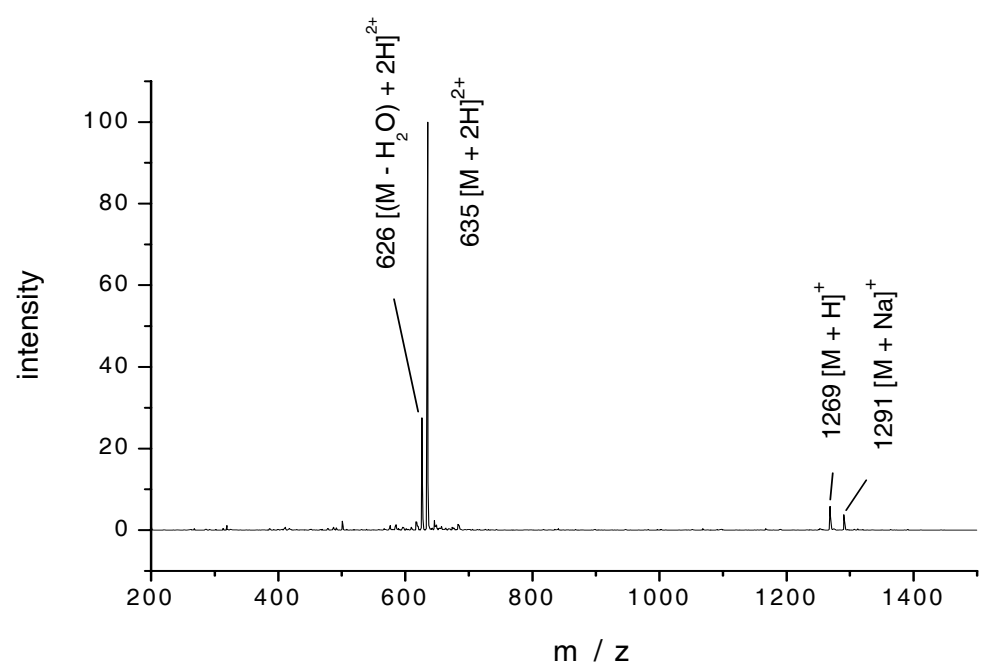

Figure S1. ESI-MS (relative detector intensity) of $\mathbf{I I}$ in methanol $\left(\mathrm{c}=0.1 \mathrm{mg} / \mathrm{mL}, \mathbf{M}_{\text {theor }}=\right.$ $1268.4 \mathrm{~g} / \mathrm{mol})$.
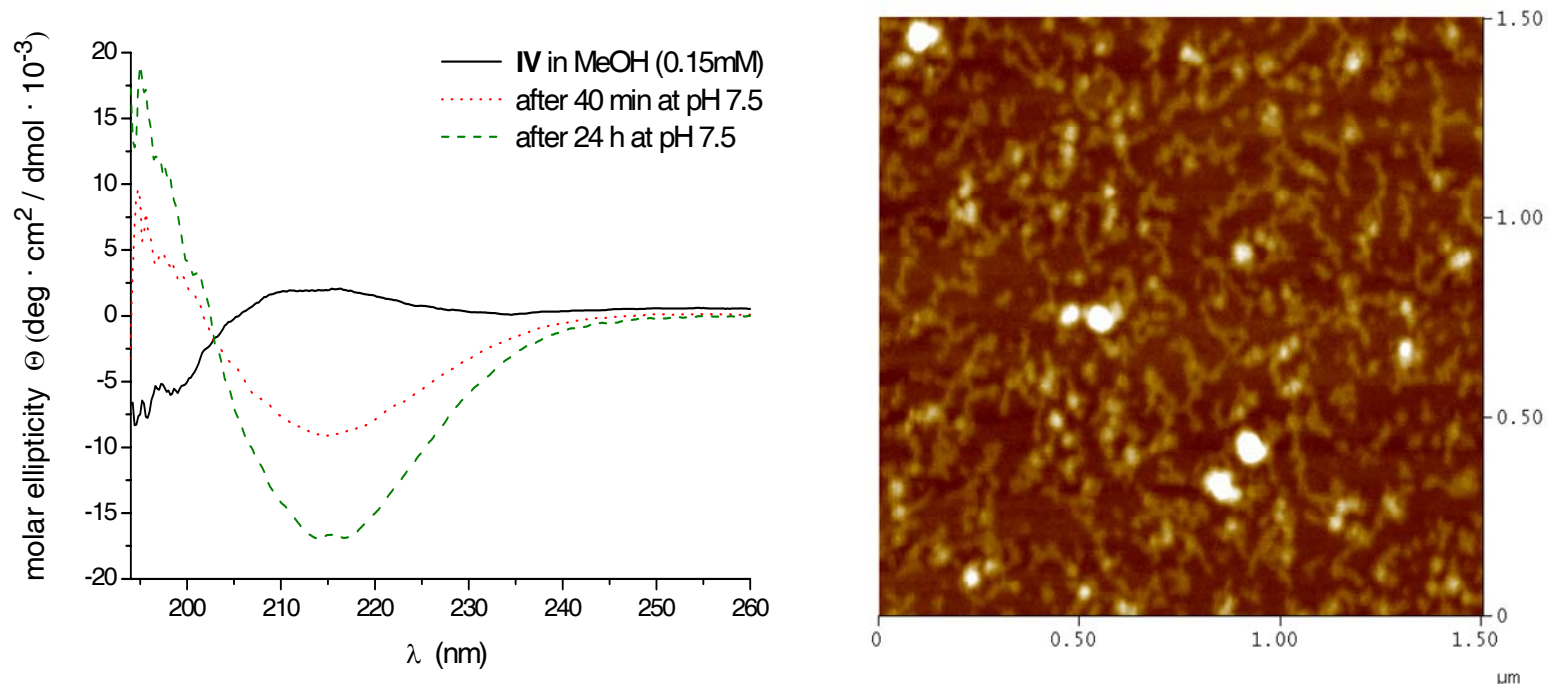

Figure S2. CD-spectra of IV in $\mathrm{MeOH}(\mathrm{c}=0.5 \mathrm{mg} / \mathrm{mL})$ prior to the switch, in methanolic $\mathrm{NaOH} 40$ min and $24 \mathrm{~h}$ after switching (left); AFM micrograph (spin coating of the solution of IV in $\mathrm{MeOH}$ (as used for CD measurements) on mica substrate; height image $(\mathrm{z}=10 \mathrm{~nm})$ ) (right). 


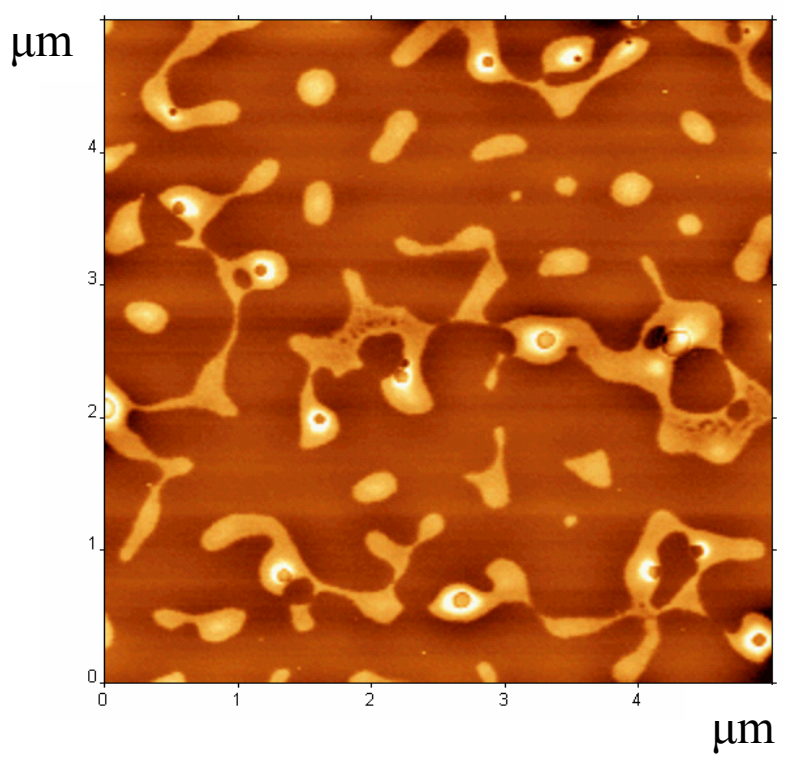

Figure S3. AFM micrograph of a solution of IV in diethyl ether/MeOH (12 vol.\% methanol, $\mathrm{c}[\mathrm{IV}]=0.25 \mathrm{mg} / \mathrm{mL}$ ) prior to the switch (spin coated on mica substrate; height image $(\mathrm{z}=$ $5 \mathrm{~nm})$.

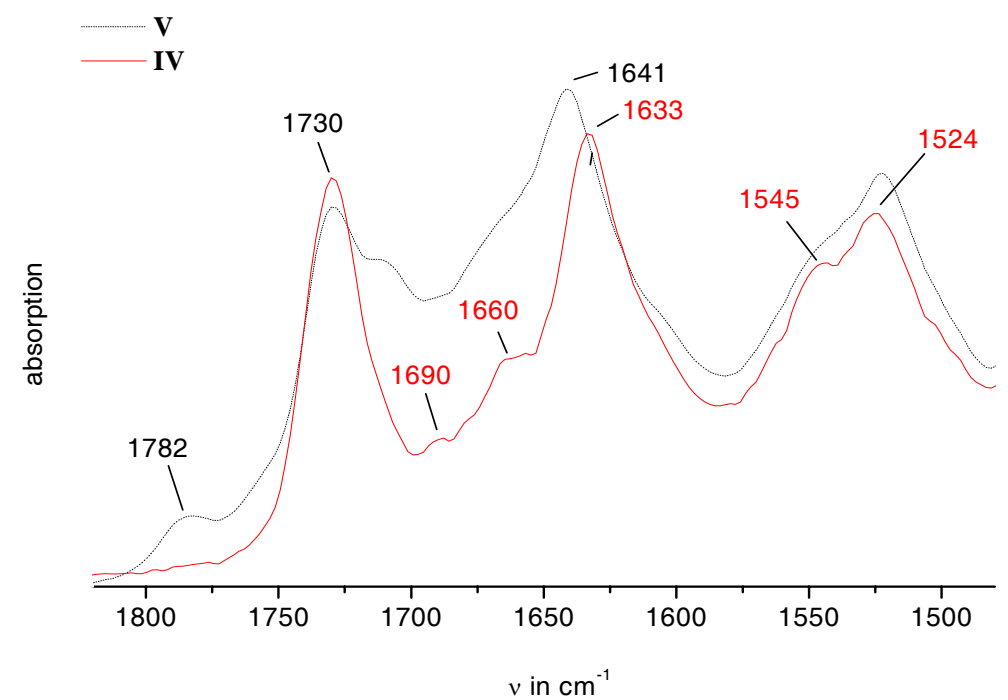

Figure S4. Carbonyl region of the FT-IR-spectrum of IV and V, showing ester carbonyl absorption band $\left(v\left(\mathrm{O}^{\text {sec. }}\right.\right.$ ester $)=1782$ and $v\left(\mathrm{O}^{\text {prim. }}\right.$ ester $\left.)=1730 \mathrm{~cm}^{-1}\right)$ and amide I and II band (statistical chain segment configuration $1641 \mathrm{~cm}^{-1}, 1524 \mathrm{~cm}^{-1}$ for IV and antiparallel $\beta$-sheet secondary structure $1633 \mathrm{~cm}^{-1}, 1690 \mathrm{~cm}^{-1}, 1545-1525 \mathrm{~cm}^{-1}$ for V) The band at $1660 \mathrm{~cm}^{-1}$ can be attributed to $\beta$-sheets adopting large loop structures. ${ }^{5}$ 


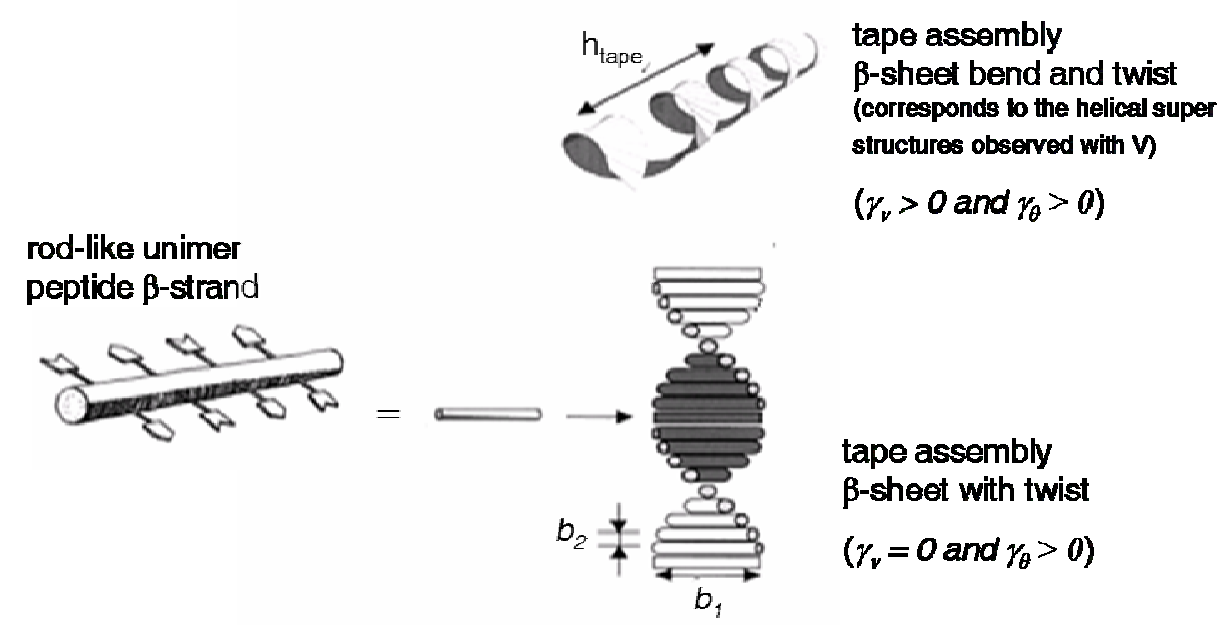

Figure S5. Model for $\beta$-sheet formation by the assembly of peptide $\beta$-strands as chiral rods.

(Reprinted with permission from Ref.6, copyright (2001) National Academy of Sciences USA).

$$
\begin{aligned}
& h_{\text {tape }}=b_{2}\left(\frac{2 \pi}{\gamma_{\theta}}\right)\left(1+\left(\frac{\gamma_{v}}{\gamma_{\theta}}\right)^{2}\right)^{-1} \\
& r_{\text {tape }}=b_{2}\left(\frac{\gamma_{v}}{\gamma_{\theta}^{2}}\right)\left(1+\left(\frac{\gamma_{v}}{\gamma_{\theta}}\right)^{2}\right)^{-1}
\end{aligned}
$$

Equations used to describe a distorted stiff tape ( $\beta$-sheet tape) consisting of a $2 \mathrm{D}$-assembly of chiral rods ( $\beta$-strands). The pitch height of the tape $h_{\text {tape }}$ and the radius $r_{\text {tape }}$ can be described by equations Eq. 1 and Eq.2, where $b_{2}$ is the distance between adjacent rods in the tape (typical $\beta$-strand distances in $\beta$-sheets are 4.63-4.75 $)$ ) and $\gamma_{v}$ as well as $\gamma_{\theta}$ are respectively the tape bend and twist angles (in radians) per unimers rod along the tape growth director. ${ }^{6}$ 


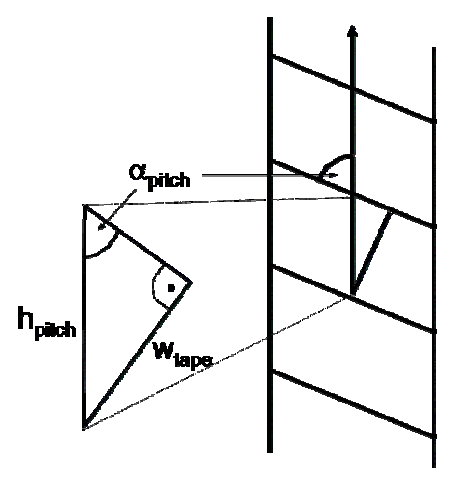

$$
\sin \alpha_{\text {pitch }}=\frac{w_{\text {tape }}}{h_{\text {pitch }}}
$$

Calculation of the maximum tape width in the helical superstructure, where $\alpha_{\text {pitch }}$ is the pitch angle, $\mathrm{h}_{\text {pitch }}$ corresponds to the pitch height and $\mathrm{w}_{\text {tape }}$ is the tape width.

1. Keller, R. N.; Wycoff, W. M. Inorg. Synth. 1946, 2, 1-8.

2. Chan, W. C.; White, P. D., Fmoc Solid Phase Peptide Synthesis: A Practical Approach. Oxford University Press: Oxford, 2000; p 346 pp.

3. Cai-AI-Yuan, P.; Lei, T.; De-Cheng, W. J. Polym. Sci. Part A: Polym. Chem. 2001, 39, $3062-3072$.

4. Rajagopal, S.; Spatola, A. F. Appl. Catal. A. Gen. 1997, 152, 69.73.

5. Surewicz, W. K.; Mantsch, H. H.; Chapman, D. Biochemistry 1993, 32, 389-394.

6. Aggeli, A.; Nyrkova, I. A.; Bell, M.; Harding, R.; Carrick, L.; McLeish, T. C. B.; Semenov, A. N.; Boden, N. Proc. Natl. Acad. Sci. U. S. A. 2001, 98, (21), 11857-11862. 